\title{
Load Carrying Capacity of a Hot Rolled Wing
}

\author{
Patrick Kaeding, Thomas Lindemann
}

\begin{abstract}
Wind turbine blades are mostly made of fibre reinforced plastics. However, in particular for the part connected to the hub steel may be used for large turbines in the future. A 3-dimensional rolling process was developed for such wing profiles, which are rolled to shape and thickness in one step. This paper deals with a practical way to access the load carrying capacity of hot rolled steel parts and to give a simple material model for design purpose. Based on systematic finite element analyses, which are compared to a 3-point bending experiment, the parameters for a bilinear material model are derived. The material model shall be suitable to reproduce the overall behaviour of the steel component so that accurate analyses are possible for structural design.
\end{abstract}

Keywords - steel, hot rolled, 3-point bending, experiment, finite element analysis (FEA), bilinear material model

\section{Introduction}

Renewable energy plays a significant role in future energy plans. Wind energy is one of the most important branches. It can be separated in on- and offshore wind turbines which differ mainly in size and material. These structures require certain 3-dimensional formed plates with variable thickness. Also in other branches of industry, e.g. shipbuilding, offshore engineering, architecture, such plates have a wide range of application. Those products all have in common that they have a big market in future and desire a simple production process with high output which is not cost intensive. That means the process should be repeatable and within a certain accuracy without too much manual input. In addition the recyclability of such products came in focus so that the material chosen for the production should meet some requirements. Therefore, the idea of rolling for a 3dimensional forming with a variation in thickness of steel plates arose. The complexity of this approach is induced by the superposition of sheet forming with a rolling process. Furthermore, such degrees of deformation have to be realized which do not exceed the material's resistance. Thus, hot steel forming has to be considered, [1], [2]. Figure 1 shows the production of a hot rolled wing profile.

Some research has been conducted on suitable material models for the forming process itself, [3], [4]. However, a material model for the steel in the final product after hot rolling is not readily available. For the purpose of structural design, a simple material model capturing the overall behaviour in yielding is required. While such a model will not reproduce the varying local material behaviour over the whole structural part - as this detailed behaviour depends on the local forming history -, it shall include the general characteristics induced by the forming process. Therefore, experimental and numerical investigations are performed for a typical hot rolled wing profile, Fig. 2, as obtained by the production process. The scan and the corresponding CADmodel of the wing profile are shown in Figs. 3 and 4.

Patrick Kaeding, Thomas Lindemann

University of Rostock

Germany

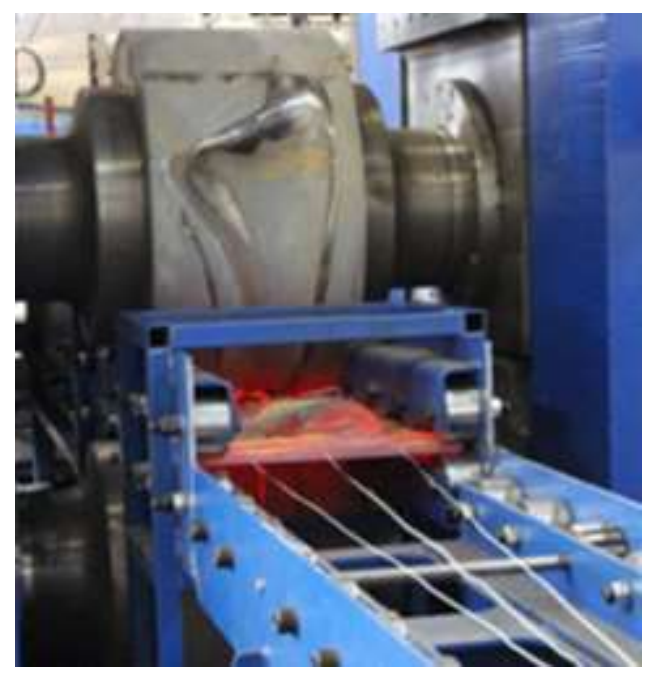

Figure 1. Production of hot rolled wing profile.

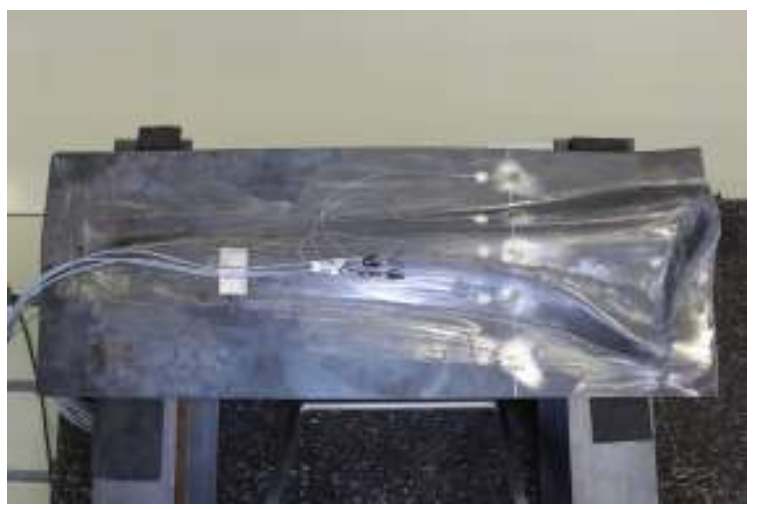

Figure 2. Wing profile - as rolled, not cut

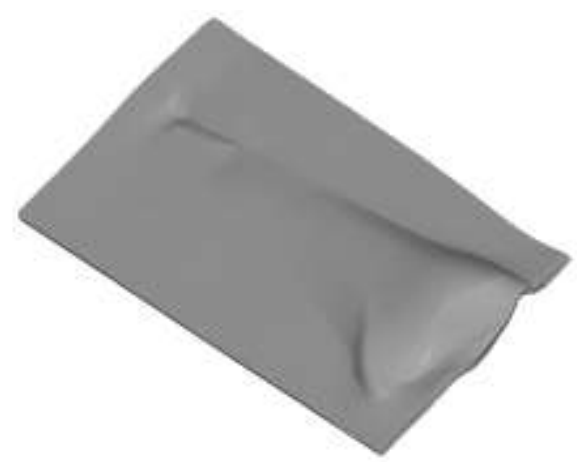

Figure 3. Scan of wing profil - as rolled, not cut

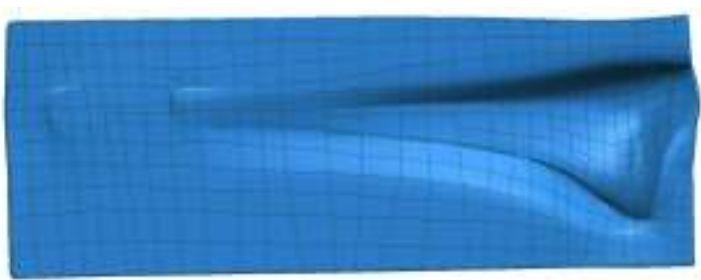

Figure 4. CAD-model of wing profil - as rolled, not cut 
Proc. of The Third Intl. Conf. on Advances in Mechanical and Robotics Engineering - AMRE 2015 Copyright (C) Institute of Research Engineers and Doctors, USA .All rights reserved.

ISBN: 978-1-63248-066-8 doi: 10.15224/ 978-1-63248-066-8-53

\section{Experimental Assessment of Load Carrying Capacity}

\section{A. Hydraulic Test Rig System}

The arrangement for a three point bending test is shown in Fig. 5. The specifications and the main dimensions of the Hydraulic Test Rig System are given in Table I and in Table II. The testing machine is a closed frame structure, which allows the application of positive or negative static and dynamic loads to large structural specimens. The base plate of the system is supported by $8(2 \times 4)$ pneumatic buffer elements, which are controlled automatically during the loading history. On the base plate $4(2 \times 2)$ columns are fixed. Furthermore, a traverse can move laterally between the columns. When the final testing position is reached, the traverse will be fixed to the columns. On the traverse a hydraulic cylinder is located to apply the loads on the specimen. The required loads are generated by one or even by two separate working hydraulic units at a maximum pressure of $21 \mathrm{MPa}$. The loading of the specimen can be applied by force control as well as by displacement control.

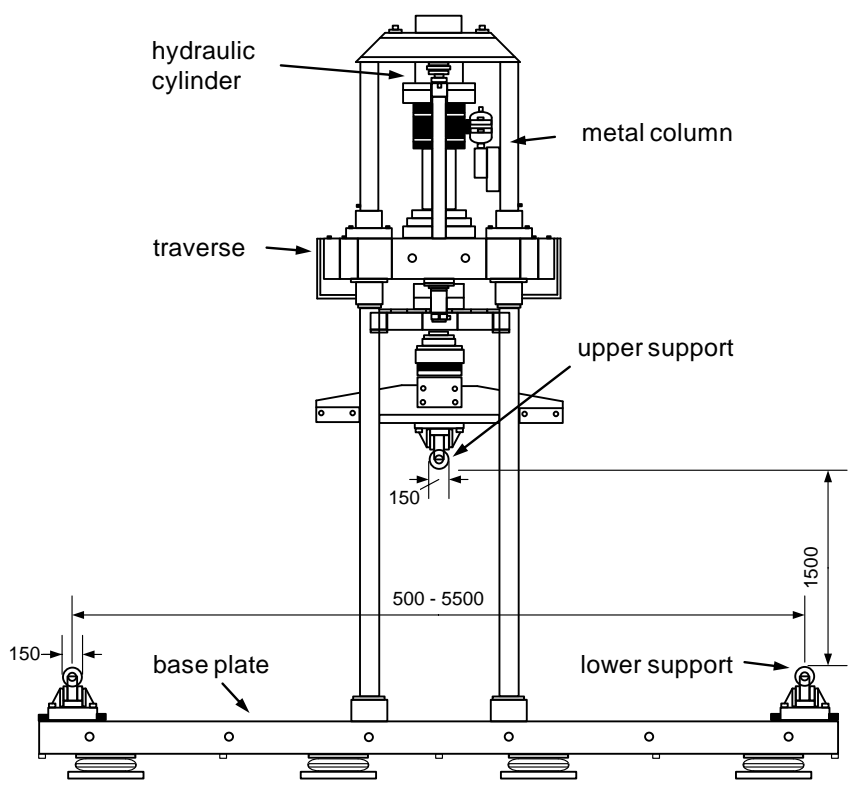

Figure 5. Hydraulic test rig system (3-point-bending)

TABLE I. SPECIFICATIONS OF HYdRAULIC TEST Rig SYSTEM

\begin{tabular}{|l|c|c|}
\hline Parameter Description & Value & Unit \\
\hline Force (static) & 1300 & $\mathrm{kN}$ \\
\hline Force (dynamic) & 1000 & $\mathrm{kN}$ \\
\hline Frequency & 10 & $\mathrm{~Hz}$ \\
\hline Cylinder stroke & 450 & $\mathrm{~mm}$ \\
\hline Traverse stroke & 1600 & $\mathrm{~mm}$ \\
\hline
\end{tabular}

TABLE II. MAIN DIMENSIONS OF HydRAULIC TEST RIg System

\begin{tabular}{|l|c|c|}
\hline Parameter Description & Value & Unit \\
\hline Length & 6000 & $\mathrm{~mm}$ \\
\hline Width & 2500 & $\mathrm{~mm}$ \\
\hline Height & 5850 & $\mathrm{~mm}$ \\
\hline
\end{tabular}

\section{B. Experimental Setup}

To assess the load carrying capacity of the wing profile, a 3-point bending test is performed. The purpose is not to validate the mechanical performance of this particular wing, but to deliver results for validating finite element analyses (FEA) to obtain the overall material behaviour. Therefore, the experiment is conducted on the non-cut profile, Fig. 2, as rolled.

The experimental setup is shown in Figs. 6, 7 and 8. As indicated in Figs. 6 and 11 the wing profile is simply supported at a distance of $1000 \mathrm{~mm}$ by two adjusted steel rolls. The load is applied off centre - closer to the support at which the more heavily deformed part is placed. This results in the maximum bending moment being applied at a section of large influence of the production process on the material properties, thus implicitly making this region govern the overall behaviour to be simulated by analyses in structural design.

The load is applied by displacement control of the piston. The experimental results of load-deflection curves are given in section IV together with the results of FEA.

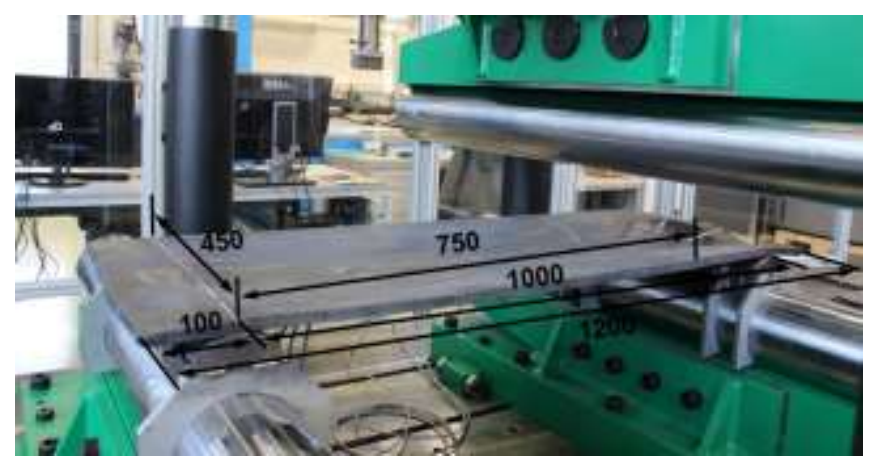

Figure 6. Experimental setup - isometric view

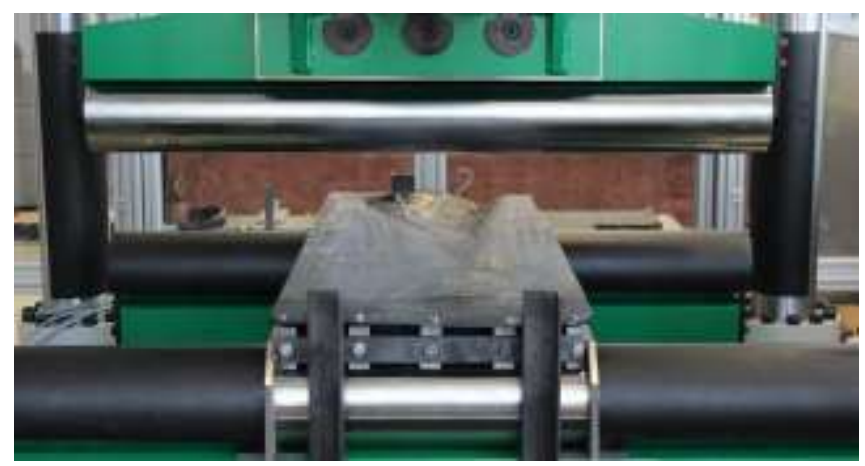

Figure 7. Experimental setup - side view

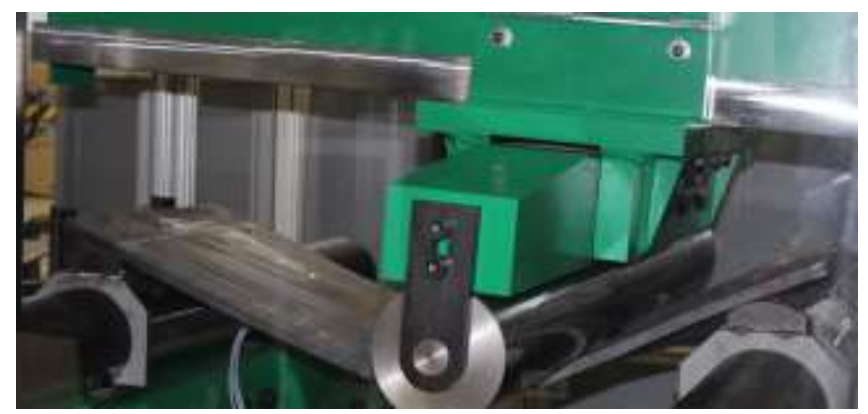

Figure 8. Deflected wing profile during experiment 
Proc. of The Third Intl. Conf. on Advances in Mechanical and Robotics Engineering - AMRE 2015 Copyright (C) Institute of Research Engineers and Doctors, USA .All rights reserved.

ISBN: 978-1-63248-066-8 doi: 10.15224/ 978-1-63248-066-8-53

\section{Numerical Assessment of Load Carrying Capacity}

\section{A. Numerical Setup}

The wing profile as rolled, Fig. 2, has been laser scanned, Fig 3, to obtain its geometry. Based on the measured data a computer-aided design (CAD) model has been developed, Fig 4, and the slightly idealized geometry is imported into the FE-software package via an IGES file, Fig. 9, showing good agreement with the real object.

ANSYS 14.5 is used for the analyses. The model of the wing profile is meshed with tetrahedral elements, Fig. 10, of type SOLID187 defined by ten nodes per element and having three degrees of freedom per node. The element is used as pure displacement formulation allowing for large deflection and plasticity. The element stiffness matrix is determined by numerical integration procedure using four integration points. To simulate contact conditions between the supports and the wing profile, the bearing rolls as well as the loading roll are idealized as rigid cylinder shells and discretized with target elements (TARGE170). This assumption is justified by the much higher stiffness of the testing machine compared to the test object. The corresponding surfaces of the deformable wing profile are discretized with contact elements (CONTA174).

Figure 11 shows the setting of boundary conditions, load application and contact surfaces. As in the experiment, load is applied by increasing the prescribed displacement at the position of the loading roll, indicated by UZ in Fig. 11.

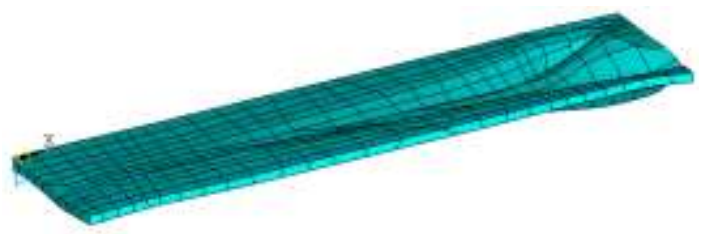

Figure 9. Geometry of wing profile - as imported from IGES file

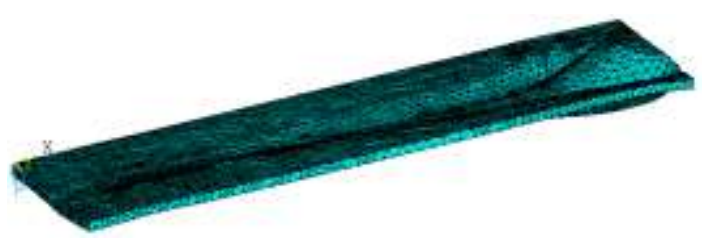

Figure 10. Finite element mesh

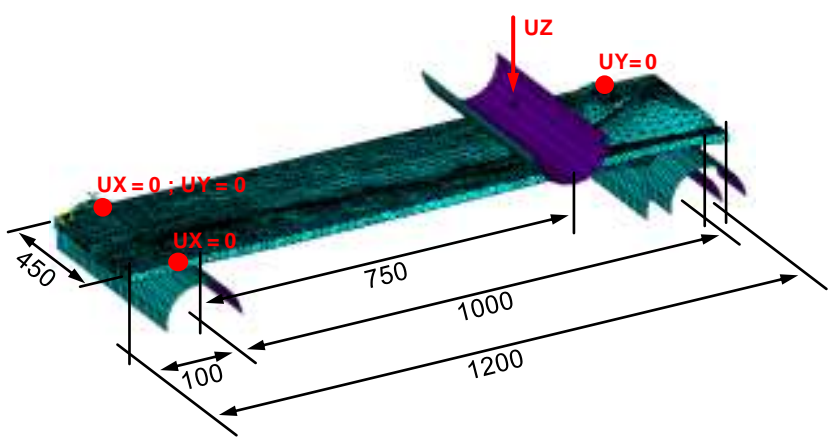

Figure 11. Finite element model with contact surfaces and boundary conditions
Newton-Raphson iterations are used in each incremental step of the quasi-static analysis. The flow rule is based on von Mises yield criterion and bilinear material law.

\section{B. Material Models}

Due to their ease of use and just four parameters for their description ( $\mathrm{E}-$ Young's modulus, $v$ - Poison's ratio, $\sigma_{\mathrm{Y}}-$ yield stress, $\mathrm{H}$ - tangent modulus), bilinear elastic-plastic material models are widely used for analyses in structural design. The aim of this paper is to find a systematic approach to obtain an overall material model for structures assembled from tailor-made hot rolled steel parts. Thus, systematic nonlinear FEA are performed with different bilinear material laws.

Figure 12 shows a bilinear material model in principle. The used models differ only in the yield stress and in the tangent modulus respectively the strain-hardening rate. The values analysed are given in Table III. Young's modulus is set to $210 \mathrm{GPa}$ and Poison's ratio to 0.3 ; the elastic regime is not changed by the production process of hot rolling. Yielding and hardening values, though, strongly depend on the exerted strain and the heat treatment of the steel plate during forming. By systematic variation, these values are selected to fit as closely as possible to the overall experimental results.

\section{Numerical Results}

Figure 13 shows the deflected shape and the spread of yielding for two analyses with different material models. The absolute results as well as the differences between the analyses are reasonable. The overall behaviour is captured in principle as observed in the experiment, Fig. 8. The numerical load-deflection curves are given in the next section for aligning the values of the material model with the experiment.

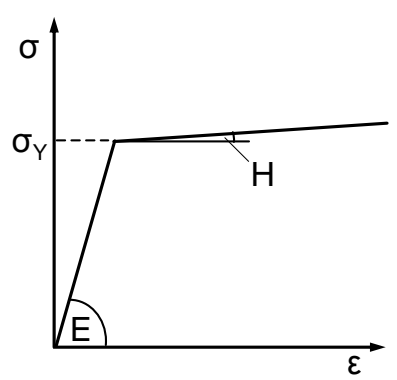

Figure 12. Bilinear material model

TABLE III. PARAMETERS OF BILINEAR MATERIAL MODELS

\begin{tabular}{|c|c|c|c|}
\hline $\begin{array}{c}\text { Yield Stress } \\
\boldsymbol{\sigma}_{\mathbf{Y}} \\
{[\mathrm{MPa}]} \\
\end{array}$ & $\begin{array}{c}\mathbf{H}_{1} / \mathbf{E} \\
= \\
1 / 75\end{array}$ & $\begin{array}{c}\mathrm{H}_{2} / \mathbf{E} \\
= \\
1 / \mathbf{1 5 0}\end{array}$ & $\begin{array}{c}\mathbf{H}_{3} / \mathbf{E} \\
= \\
\mathbf{0}\end{array}$ \\
\hline 165 & $X$ & $X$ & $X$ \\
\hline 185 & X & $X$ & X \\
\hline 205 & $X$ & $X$ & $X$ \\
\hline 225 & & & $X$ \\
\hline 255 & $\mathrm{X}$ & $\mathrm{X}$ & X \\
\hline 319 & $X$ & $X$ & $X$ \\
\hline 355 & $X$ & $\mathrm{X}$ & $X$ \\
\hline
\end{tabular}




\section{Iv. Comparison of Experimental and Numerical Results}

The load-deflection curves obtained by FEA with the different material models are compared to the experimental load-deflection curve. The deflection at the position of load application is not the largest deflection of the bending curve of the wing. Typical differences between the lateral deflection UZ at load application and the maximum deflection $U_{\max }$ are indicated in Fig. 13. However, the overall behaviour is best described by taking the prescribed deflection UZ in the following graphs.

As the wing considered here has been rolled out of a steel plate originally having a nominal yield stress of $355 \mathrm{MPa}$, material models with this yield stress and lower ones are considered. The structural behaviour of the wing in 3 -point bending determined by nonlinear FEA is presented in Fig. 13, exemplarily. The nominal yield stress is applied for different tangent modulus values to determine the hardening influence on the load carrying capacity of the wing. The maximum bending moment occurs at the load application region (loading roll) and it decreases linearly to the lower supports (bearing rolls). Due to the variation of the wing profile shape in the longitudinal, transverse and thickness direction the moment of inertia decreases from the load application region to the left support but increases to the right support. During the loading history yielding starts on the outer surfaces of the rolled out wing at half length approximately and spreads over the thickness as well as in longitudinal direction.

In Figure 13 the stress ratio distribution $\left(\sigma_{\text {eqv }}-\right.$ equivalent von Mises stress, $\sigma_{Y}-$ yield stress) is presented for the applied lateral deflection value of $U Z=50 \mathrm{~mm}$ (loading roll). Under consideration of a tangent modulus of $\mathrm{H}=1 / 75 \cdot \mathrm{E}$ the yield stress is exceeded in the centre region of the wing and the maximum deflection $U_{\max }$ is smaller compared to a linear elastic-ideally plastic material model $(\mathrm{H}=0)$. The stress ratio decreases to the ends but the distribution is very similar for both models. To describe the overall behaviour and the influence of the material models on the load carrying capacity, the corresponding loaddeflection curves are compared to the experimental results.
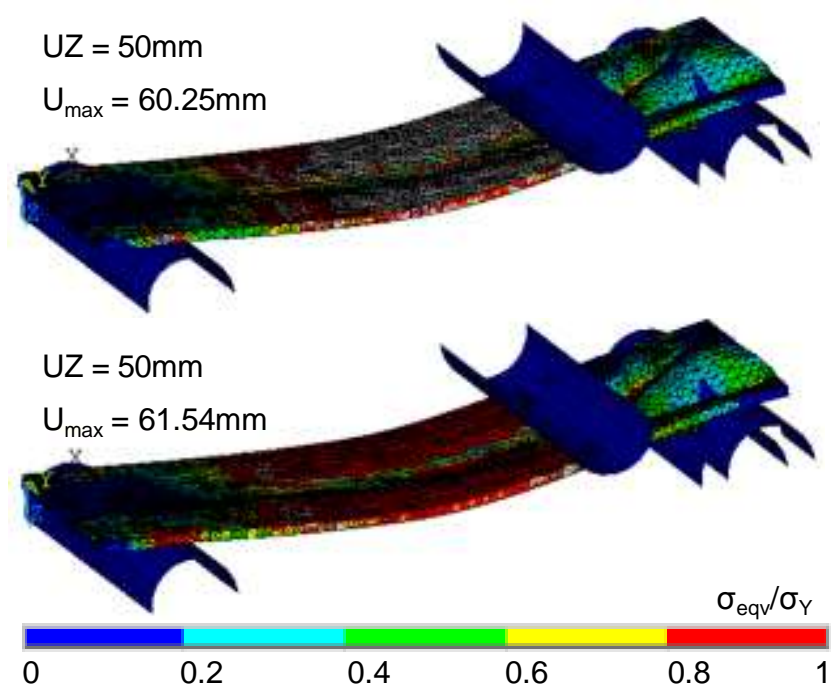

Figure 13. Deflected shape and spread of yielding for $\sigma_{\mathrm{Y}}=355 \mathrm{MPa}$, $\mathrm{H}=1 / 75 \cdot \mathrm{E}$ (top) and $\mathrm{H}=0$ (bottom)
Results obtained with a tangent modulus of $\mathrm{H}=1 / 75 \cdot \mathrm{E}$ are shown in Fig. 14 for different values of yield stress. Respective results with $\mathrm{H}=1 / 150 \cdot \mathrm{E}$ are given in Fig. 15 and with $\mathrm{H}=0$ in Fig. 16. When the tangent modulus decreases the maximum load carrying capacity also decreases. When the yield stress decreases the load carrying capacity of the wing decreases, too. Only for low yield stress values without strain-hardening $(\mathrm{H}=0)$ the applied lateral deflection value $\mathrm{UZ}$ is lower than $50 \mathrm{~mm}$ for numerical stability reasons.

It is easily seen that the yield stress after hot rolling is significantly lower than the original yield stress of the base material. The lower the tangent modulus, the earlier the load-deflection curves that in principle fit to the maximum load of the experiment deviate from the slope of the experimental curve. Therefore, a significant hardening rate is effective in the hot rolled material. The overall best fit to the experimental curve is obtained (in a conservative sense of design) with a yield stress of $185 \mathrm{MPa}$ and a tangent modulus of $\mathrm{H}=1 / 150 \cdot \mathrm{E}$.

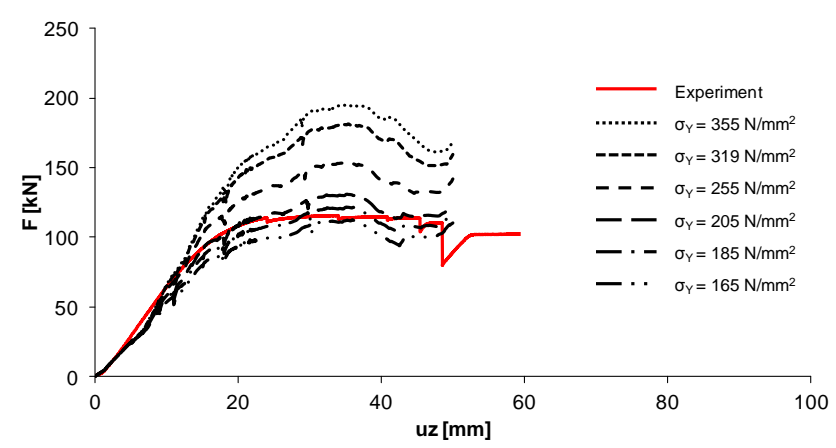

Figure 14. Load-deflection curves for different values of yield stress and a tangent modulus of $\mathrm{H}=1 / 75 \cdot \mathrm{E}$

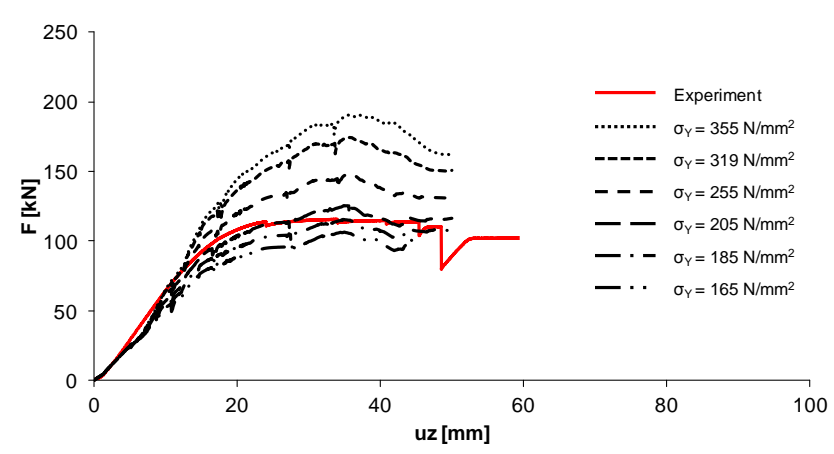

Figure 15. Load-deflection curves for different values of yield stress and a tangent modulus of $\mathrm{H}=1 / 150 \cdot \mathrm{E}$

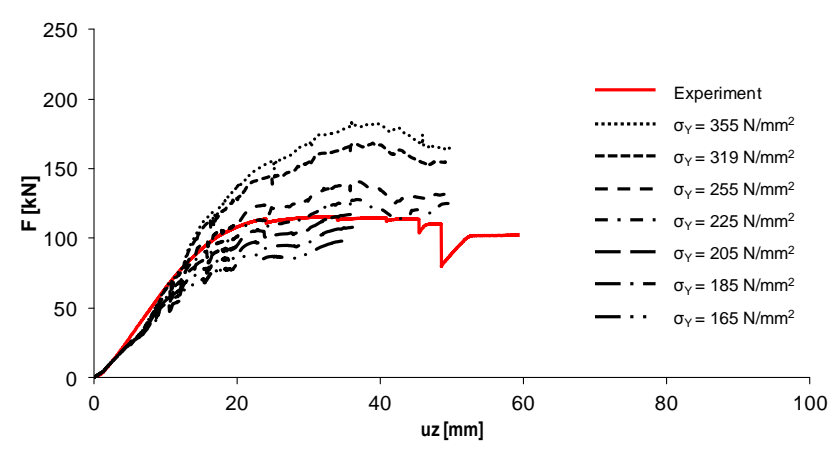

Figure 16. Load-deflection curves for different values of yield stress and without strain-hardening $(\mathrm{H}=0)$ 


\section{v. Conclusions}

A hot rolling process was developed in previous studies, [1], [2], for rolling of steel plates simultaneously to shape and to thickness. Such a production process offers high potential for complex steel shapes as they may be used in the future in different applications of wind energy, ocean engineering and related fields of architecture and ship building industries.

So far, only studies on material models that govern the production process, [3], [4], were performed. However, for structural design using such hot rolled steel parts, a simple material model is required that describes the overall behaviour of such structural components.

In this paper, a systematic approach consisting of a 3 point bending test of a hot rolled steel part and nonlinear FEA using a bilinear elastic-plastic material model has been demonstrated. Based on measured data of the hot rolled steel part a geometry model has been developed and used for an appropriate FE-model. The wing is discretized by tetrahedral solid elements and contact conditions are defined between the supports and the steel structure. The load carrying capacity is determined for different material models. By changing yield stress and tangent modulus value, a best fit to the experimental behaviour of the structural part as a whole is obtained, thus giving a simplified material model suitable for design purpose.

It is seen that the material behaviour of the hot rolled steel part significantly differs from the behaviour of the base material as it is documented e.g. in [5]. To assess the global material behaviour for the design stage, the approach shown here is very well suited. Detailed tensile tests of several specimens taken from different locations of the hot rolled product certainly give more detailed insight into the locally different material behaviour after rolling. However, the approach shown here is a good alternative to obtain an "integral" material model for structural design.

\section{Acknowledgment}

The project that is the basis for this report is funded by the ministry of economics, labour and tourism of the German state of Mecklenburg-Vorpommern and the European Union within the programme "European Funds EFRE, ESF and ELER in Mecklenburg-Vorpommern". The financial support of the project "Process Development for the Three-Dimensional Complex Forming of Heavy Plates" is acknowledged. The Hydraulic Test Rig System has been funded by the DFG (German Research Foundation) and the German state of Mecklenburg-Vorpommern. It has been built by FORM+TEST Seidner \& Co. GmbH. The figure of the wing production is used courtesy of Ostseestaal $\mathrm{GmbH}$.

The content of this publication is the sole responsibility of the authors.

\section{References}

[1] M. Bojahr, H. Prommer, R. Tschullik, P. Kaeding, "3-Dimensional Forming of Thick Plates - A Comparison of Deep Drawing and an Approach of Rolling and Bending within a Single Process", LSDYNA-Conference, Strasbourg, 2011.

[2] H. Prommer, M. Bojahr, R. Tschullik, P. Kaeding, "Thick Plate Rolling - a Numerical Approach in Comparison with Analytics and Experimental Data", American Institute of Physics, ESAFORM, Belfast, 2011

[3] K. Krebes, U. Ruppin, R. Tschullik, P. Kaeding, "Iterative Extrapolation method of test data for forming simluations", Ch. 18 in: J.T. Cieslinski, J.A. Szymczyk (Eds.), "Developments in Mechanical Engineering”, Vol. 5, Gdansk, 2012: pp. 173-180.

[4] K. Krebes, G. Tober, M. Bojahr, R. Tschullik, P. Kaeding, P. Maier, "Research Study on Structural Low Carbon Steel Establishing a New Thick Plate Forming Process", in: K. Mori, M. Pietrzyk, J. Kusiak, J. Majta, P. Hartley, J. Lin (Eds.), "Steel Research International", special edition: $14^{\text {th }}$ Int Conf. Metal Forming, Krakow, 2012, pp. 939942

[5] M. Spittel, T. Spittel, "Steel symbol/number: S355J2G3/1.0570", in: Warlimont, H. (Ed.). "SpringerMaterials - The Landolt-Börnstein Database", http://www.springermaterials.com, DOI: 10.1007/978-3540-44760-3_30, Springer-Verlag, Berlin, Heidelberg, 2009. 